\title{
The Affordances of Fiction for Teaching Chemistry
}

\author{
Randy K Yerrick*, Tiffany Simons \\ Department of Learning and Instruction, University at Buffalo, SUNY, Buffalo, NY, USA \\ *Corresponding Author: ryerrick@buffalo.edu
}

\section{ABSTRACT}

As science fiction has a way of capturing the human imagination that few other genres can rival, this study sought to investigate the effects of using science fiction on the performance and interest of high school chemistry students. An action research approach was used to guide the first author's practice as she studied two college preparatory chemistry classrooms. One class was used as a control group and received traditional chemistry instruction through lecture and labs. The second class was provided with supplemental excerpts of science fictional reading and film. Student scores on a pre-assessment and post-assessment achievement test items were analyzed and supplemented with student interviews and field note observations, and a teacher reflective journal was used to complement achievement data and inform findings regarding the effectiveness of including fiction as a pedagogical choice. Implications for this study on teaching tools, methodologies, and curriculum development are discussed.

KEY WORDS: chemistry, science, high school, action research

\section{INTRODUCTION}

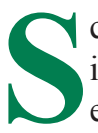
cience fiction has a way of capturing the human imagination that few other genres can rival. Many educators have attempted to leverage this fascination to educate the general public pondering such questions as, "Can i tap into the students' intense interest in popular fiction movies to actually teach teenagers something useful?" This contemporary supposition actually follows a long litany of queries as the use of fiction for teaching science precedes the cultural icons of H.G. Wells' War of the Worlds and Gene Roddenberry's Star Trek. As far back as Greek literature, fictitious places and physical elements populate stories of orators, like the mythical element Orichalcum, a gold-colored metal, was fabled to have been used in the construction of the Temple to Poseidon and Cleito on the Island of Atlantis (Ober and Krebs, 2009). There have been many reasons educators have given for promoting the use of fiction for teaching science. A non-exhaustive list of proposed affordances for using fiction for teaching chemistry include: (a) Increasing student interest, (b) expanding interests of non-science students and crossdisciplinary study, (c) creating critical consumers of media, and (d) exploring real and proposed threats to the environment we inhabit. We explore several of these rationales below for framing our approach to teaching chemistry through fiction.

\section{LITERATURE REVIEW}

\section{Increasing Interest}

The most widely cited support for incorporating video fiction as a pedagogical approach for teaching science rests on claims that it increases learner interest. We use the term fiction here to encompass a variety of sources of media, which include, but are not limited to, widely recognized dominant genres of film and literary contributions. For example, readers may recognize Star Trek and War of the Worlds as examples of classic science fiction resources, another fiction film, television, and literary contributions may be categorized as fiction but only incorporate science content for accomplishing a plot, theme, or character development (e.g., Breaking Bad, Big Hero 6, Harry Potter). One of the affordances of incorporating the broader collection of fiction in the science classroom is that it has been shown to cultivate student interest in science, even among non-science students (Dubeck et al. 1990; Laprise and Winrich, 2010; Lin, 2014; Marks, 1978; Surmeli, 2012). Milanick and Prewitt (2013) employed media from popular TV shows to illustrate how basic chemical concepts can help them solve complex physiological and medical problems. Although most scenarios presented to students were improbable, the incorporation of drama, fiction, and real-life scenarios created a demonstrable increase in students' interest in concepts being taught. Even in higher education, fiction video excerpts have been used to increase interest in science (Milanick and Prewitt, 2013). Laprise and Winrich (2010) integrated science fiction films into upper-level electives for non-science majors. The students in the study stated that they felt the courses were more interesting and that viewing the films and analyzing the scientific fallacies were helpful in understanding the course concepts. Science fiction videos served multiple purposes in these courses, including the elucidation of commonly held science misconceptions, which the instructor could use as a response platform for future instruction (Laprise and Winrich, 2010).

In more carefully controlled studies, the selection of video clips designed to peak student interest has been demonstrated to have a more optimized effect when instructor and student perceptions 
are closely matched. Frey et al. (2012) demonstrated that movie clips can provide a strong cognitive anchor to contextualize the concept within the instruction. The most impactful clips were found to be ones which instructors selected popular actors, incredible sets, memorable dialog, and memorable special effects endemic to the content being taught (Frey et al., 2012). Examining student and teacher perceptions of fiction videos as well as the provision of appropriate pedagogical strategies provided the greatest impact on students' interests.

\section{Making Cross-disciplinary Connections}

Fiction videos have great cultural traction among students beyond traditional curriculum. This is due in part to the fact that all kinds of students watch fiction, not just science students. A movie like Harry Potter and the sorcerers' stone has rallied strong attraction across the age and interest spectra. As such, it can leverage more universal appeal for a broader student audience. Authors as notable as Asimov (1967) have seen fiction as a means to increase science interest and guide future scientists and the general population. Several researchers have claimed that fiction videos can increase student motivation for learning across curricular content boundaries (Surmeli, 2012; Dubeck et al., 1990). Films like the series Harry Potter and Jurassic Park or the films Armageddon, The Time Traveler's Wife, 2012, and Twilight are intended to be interdisciplinary (including the softer sciences, mathematics, politics, and society) and therefore will interest more students in scientific topics. Arguably selected fiction excerpts which include a significant historical background would not only interest the strong science student but also the history student as well.

In some contexts, fiction films have been used to inspire creativity as well as improve cognitive function. Among pre-high school-aged children, the impact of fiction has been examined for its impact on narrative and literacy. Students have demonstrated increased awareness of technical and scientific matters, as well as becoming more expert of the social context of the process of building science (Morais, 2015). Lin (2014) found middle school students exposed to learning environments where fiction films were used performed higher on pre- and post-creativity tests and that student of varied cognitive strengths and approaches to learning did not differ in the impact. In higher education contexts, university professors have recognized important differences among undergraduates arriving to their science programs and have devised courses incorporating a crossdisciplinary approach to engage more students than the typical high-achieving, science majors in their general education science requirements. Some college faculty has taught science to non-science majors through courses designed to teach across disciplinary content in thematic ways. In science courses about the application of science to societal issues such as environment, conservation, and sustainability, college faculty are integrating popular movie excerpts for the purpose of creating additional interest among undergraduate student populations (Brzenk et al., 2000). While such courses are generally popular and inspire greater student interest in science and thematic topics, there are only loose connections made to kinds of educational outcomes and achievement valued in today's high-stakes testing environment. Relatively few studies identify specific impacts of science fiction learning opportunities to any specific achievement data, which leaves many questions, open regarding the value of devoting valuable instructional time to seemingly peripheral interests. Even in the educational research literature, it remains an unresolved matter whether the inclusion of science fiction contributes any valuable educational outcome over standard delivery approaches and the strict maintenance to a traditional lecture orientation toward science instruction.

\section{Preparing Critical Consumers of Media}

A strong criticism of society's current media rich and mobile connectivity informational context has been that an unfettered and relatively uncritiqued consumption by students presents far too much misinformation and produces an intellectually nonrigorous consumer mindset among learners. Scholars note the increased use of smart devices and suggest their influence creates an effect on learners, which diminishes the cognitive functions and practices of their user (Carr, 2011; Oppenheimer, 2003). If these scholars are correct, such an approach can be problematic when you consider the multitudes of 'scientifically illiterate' American citizens. Scientific literacy is defined as the ability to understand and explain scientific concepts and facts at the basic level and use technological advancements in life (Surmeli, 2012). Some scholars have argued that only a relative minority of current U.S. citizens are classified as scientifically literate (Clough, 2011; Miller, 1983; 1987).

Working against scientific illiteracy may involve the use of fiction in the classroom to connect scientific ideas to the lives and cultures of modern youth. It can present opportunities to critically discuss ethical and, possible, political influences of scientific thinking and processes in society. There are counter-science examples and pseudoscientific approaches that misapply scientific concepts in blatantly inaccurate ways among fiction examples. Pseudoscience is referred to as fields of study, which copy the practices of science, come to conclusions, but do not have consistent evidence to prove the claims. Without the appropriate scientific knowledge, these beliefs in pseudoscience can lead to a misunderstanding of scientific laws and principles. Critiques of inaccurate fiction films like Star Wars and other popular films serve as excellent opportunities confront misconception and misapplication of scientific concepts. Researchers have also argued that the use of fiction cannot only improve high school students' interests and attitudes toward science it can also assist in the development of conceptual understanding of science constructs as well (Dubeck et al., 1990). After Dubeck et al.'s study, educators began to train each other to use fiction in the classroom. Researchers also found that using fiction at the high school level could help distinguish between scientific and pseudoscientific approaches. Lin (2014) also found increased interest among middle school students when fiction films were used. 


\section{Addressing Ethics and Societal Issues of Science}

For more than four decades, science educators have examined fiction as way to provoke public discussion of ethics in science-related fields (Dubeck et al., 1990; Frayling, 2013; Hofstein and Kempa, 1985; Labianca and Reeves, 1981; Liberko, 2004, Marks, 1978; Nunan and Homer, 1981). Science fiction more specifically has been used to promote thoughtful class discussion regarding larger global human issues like sustainability through movies like Soylent Green (1973), pandemic phenomena through films like The Andromeda Strain (1971), or genetic engineering in films like Jurassic Park (1993). Interestingly, many of the science topics included in early science fiction examples have gained new traction with increased public attention and scientific evidence. This is perhaps most clearly visible in the attention given to the case for global warming and sustainability that was rarely if ever included in the fiction films of the 60's and 70's. For example, Soylent Green (1973) was considered in its day a far-fetched extrapolation of human exploitation of the environment and the movie's implicit sustainability, and global stewardship messages have now re-emerged as central societal issues in global headline news.

Many of the recommendations for incorporating fiction into instruction is based on the assumption that students who are more thoughtful and reflective of multiple varying worlds and possibilities can apply this kind of thinking outside of class to current societal issues. To demonstrate this, some have used fiction in the educational realm to increase student creativity and problem-solving (Marks, 1978; Surmeli, 2012). Problemsolving capacity and design have also been shown to increase. For example, Lin (2014) used films like transformers during instruction to compare the designs for tasks like vehicles traversing various barriers (Lin, 2014). The experimental group who observed excerpts from transformers outperformed control groups of traditional instruction in design challenges. In his research-based instruction, Lin (2014) recommended giving students more time to focus on the "new" techniques before assessment and explained that showing more video clips throughout a course allowed for a better understanding of concepts and processes. Surmeli (2012) also demonstrated that students had an increased success in science, demonstrated expanded creativity, and excelled in problem-solving over traditionally taught students.

Studies have revealed that students' beliefs need to be explored regarding their application of science concepts and implicit understanding of science as a discipline. Students can stubbornly retain unexplored beliefs including a representation of science as value-free, ethically neutral, and completely objective (Nunan and Homer, 1981). When science is treated this way, essential conversations of science ethics are rarely incorporated into classroom discussions as many scholars argue it should be (Lemke, 1990). In contrast, controversial topics such as building weapons of mass destruction or biomedical engineering have often avoided strong societal critique when treated only as "necessary evils". Nunan and
Homer (1981) argued scientific knowledge should be taught as a belief system that may preserve social order and the use of fiction may allow students to link school science and real science to societal issues and to analyze scientific principles in social contexts (Nunan and Homer, 1981; Surmeli, 2012). These researchers argue that students who are capable of considering broader implications of science and who know the implications and values of scientific principles are better able to make informed opinions on controversial contemporary topics (Laprise and Winrich, 2010; Marks, 1978). Although the prospect for using fiction to exploring science and societal issues is long-standing, the use by teachers and the potential continues to remain untapped according to research.

\section{Science Fiction in the New Era of Science Education Reform}

In recent science education research, video has been explored as a medium for science educators to introduce fiction for the purpose of expanding the minds of young science students (Chandler, 2002; Dark, 2005; Frey et al., 2012; Lin, 2014). Regardless of the nature of the delivery media, whether the inclusion of H.G. Wells print novels or modern digital film, science educators have argued for years that the inclusion of fiction and not just objective facts can be a strong motivator for learning and venue for enhancing deeper understanding of science as a discipline (Bixler, 2007; Cruz, 2013; Dark, 2005; Liberko, 2004; Milanick and Prewitt, 2013). Although the incorporation of science video media into classroom instruction has vast applications, few have studied the process and with enough scrutiny to connect science achievement with the introduction of science fiction. Only a few studies have adapted such a research view of the topic. Among the small collection of studies, some researchers have observed the introduction of science fiction as a means to make cultural connections with students through pop culture movies. Researchers reported increased: Interest and ability to critically view the world, curricular connections across content, ability to address misconceptions, and student interest in pursuing science careers (Dark, 2005; Flynn, 2010; Harwood and McMahon, 1997; Hofstein and Kempa, 1985; Lin, 2014). Most have cautioned against inappropriately applying their findings of an impact as a complete solution for addressing barriers science teachers face. For example, the insertion of fiction video cannot directly mitigate or eliminate the misconceptions bring to class nor the common sense ways they may go about making sense of everyday phenomena. Many issues are in fact only resolved with more complete multipronged pedagogical, curricular, and assessment approaches emphasizing the role of teachers and instructional practices over the insertion of media itself (Oppenheimer, 2003).

Despite the varied interpretations of existing studies examining the use of fiction in teaching science, there are many reasons to consider integrating fiction into classroom chemistry instruction to improve science achievement and students' understanding. Among them, current science education reforms call for richer representations of scientific 
literacy in curriculum and in assessments as supported by new visions for science education (Moje et al., 2004). For example, the discourse norms promoted in current science education reforms of PISA (Cresswell and Vayssettes, 2016) and the Next Generation Science Standards (NGSS Lead States, 2013) reflect the development of arguments, experimentation, and explanation of real-world phenomena (Bybee et al., 2009). They emphasize the social context, which surrounds the co-construction of scientific knowledge using evidence and the acquisition of scientific literacy which supports students to speak, think, act, and communicate within a community of experts. Specifically, NGSS scientific literacy refers to the ability to use scientific knowledge to explain phenomena and draw evidence-based conclusions about science-related issues. Moreover, the NGSS notion of literacy incorporates an international perspective of promoting dispositions of reflective citizens toward sciencerelated issues:

From an international perspective, science and engineering practices are seen as necessary for literacy as well as proficiency. The OECD's Programme for International Student Assessment 2015 Scientific Literacy Assessment Framework (2012) states that a scientifically literate person is able to engage in discourse by explaining phenomena scientifically, evaluate and design scientific enquiry, and interpret data and evidence scientifically (NGSS Lead States, 2013. p. 379).

To successfully promote a new kind of scientific discourse, teachers must come to understand the contextual components impacting science learning (Rodriguez, 2015; Rodriguez and Kitchen, 2005). Competent teachers must be able to promote and navigate the contemporary conversations of science and society and understand ways children can and should appropriate such critical thinking (Lumpe et al., 2000; Mintzes et al., 2005). Students are not "Blank Slates" and do not arrive to classrooms without lived experiences and knowledge. Children bring with them a wealth of experience and knowledge that can be a great asset in learning science, and teaching in ways that embrace and leverage such resources requires that teachers make efforts to first become aware of and then take advantage of these linguistic and cognitive tools. Teachers can have access to the cultural knowledge, understanding, and resources (like video media) students bring with them, and science fiction which is so prevalent in the popular movies which most U.S. students flock to can serve as a tool to bring students' understanding of the world into the classroom. These opportunities can be leveraged to better recognize students' needs and view students' thinking through a new orientation lens and to envision classroom science discourse as a means to encourage students to think more critically about the events and media which surround them. To this end, we asked the following research question, in what ways, if any, can the insertion of science fiction impact students' learning of core chemistry concepts?

\section{METHODOLOGICAL APPROACH}

\section{Data Collection and Analysis}

This study began as a collaborative action research project in which the first author explored the use of fictional supplements to a traditional pedagogical approach to teaching chemistry. The first author was a white, veteran, female chemistry teacher accountable for four daily classes of Junior and Senior high school students in an urban school in the Northeastern U.S. After years of tepid growth of students' learning surrounding chemical change, the first author together with her graduate advisor to study collaboratively her teaching the subsequent year. An action research project seemed to be the most reasonable as it provided a template through which to manage the insertion of non-traditional curricular resources and allowed both authors to explore collaboratively the students' interpretation as well as their application of supplemental content resources (Carr and Kemmis, 1986; McTaggart, 1996). It provided a flexible approach to changing classroom discourse as a means toward school improvement through critically informed action and reaction, which is appropriate to the real, complex, and often confusing circumstances and constraints of the modern school (Kemmis and McTaggert, 1988). We were primarily interested in the discussions and connections students made in the context of classroom discourse when presented with fictional supplements. We also examined the progress made in more clinical settings through structured interviews and pre- and post-assessments. We wanted to know how students made sense of science concepts embedded in fiction-based excerpts both before and after 4 weeks of instruction. We conceptualized of the role of participant teacher (first author) and outsider researcher (second author) due to our need to use action research to improve circumstances and understandings of personal and professional dimensions of classroom participation (Kemmis, 2010; Ryan, 2009). During the $1^{\text {st }}$ year's pilot study, the instructor experimented with a variety of media and surveyed students with regard to the most engaging examples she introduced. During this time, she also kept a reflective journal of her own practices and observations of students; noting students' responses to pedagogical approaches she used as well. The first author employed science fiction excerpts in a variety of ways including: (1) Introduction of topics vis-à-vis discrepant fictional events, (2) exemplars of embodied concepts following traditional instruction, (3) fictional artifacts for small group student debates, (4) complements to lecture to open up student questions during traditional lectures, (5) venues for follow-up applications after teaching concepts, and (6) artifacts for student prompts facilitating formative assessments.

During the second implementation of classroom pedagogy in the following year, rigor was applied to the data collection design. First, fictional resources were evaluated and strategically planned for the instructional unit well in advance. These planned insertions were informed by teacher field notes from the prior year and coordinated with data gathering during the unit of study. Through the instructor's observations and 
field notes, the pedagogical approaches that rendered the most student responses and the richest student contributions were the uses of fiction in a discrepant event prior and during brief mini-lectures $(<10 \mathrm{~min})$ and the insertion of fiction as an artifact of small group instruction for students to critique the accuracy of and application to real-world events. During these small group student-led discussions, the teacher would rove between groups, listening and taking notes on student discussions.

The high school chemistry unit where fiction was used taught chemical change and reactions, balancing products and reactants, and categorization (e.g., single replacement, double replacement, synthesis, and decomposition). Typically, students showed difficulty in learning fundamental chemistry concepts such as conservation of mass and the nature of chemical changes and bonds. This was revealed through prior assessments and the pilot from the prior year. By design, one class intentionally represented instruction from years past, and one class treatment included the insertion of fictional excerpts to an instruction to prompt student discussion. In the first class, the teacher intentionally used real-world examples of chemical changes and labs from previous years in her instruction which included several lab experiences sprinkled in with high school lectures and practice problems for a traditional treatment of stoichiometry and balancing reactions, and reaction classification. For the second modified class, students were given fiction examples to complement instruction as a part of teacher-led discussion as well as student-led small group work. Each fiction insertion was accompanied by an experiment or activity. Students were asked to critically examine the inserted media or text, finding relationships between the fiction and classroom practice, even in instances where depictions were clearly inaccurate scientifically.

During the 4 weeks of instruction, 49 students participated in the study - 25 in the first group receiving traditional instruction representative of the teacher's past practices and 24 in the experimental group inserting fiction during instruction. Students in the intervention group viewed various fiction examples at appropriate application points of instruction, intentionally addressing various conceptual questions, identified by the teacher as fruitful avenues to capture student thinking. These topics included mass conservation (e.g., "Is mass conserved in this example?"), reaction classification (e.g., "Are explosions oxidation or some other reactions type?"), and the nature of chemical changes (e.g., "Where does the oxygen come from in this example of combustion?"). These interventions are represented in Table 1.

As a part of the action research approach, a quasi-control experimental design was introduced in the first author's classroom: 1 classroom block of control and 1 classroom block of intervention. Blocks are set at $84 \mathrm{~min}$. Pre- and post-assessments were gathered regarding students content understandings, and student interviews were facilitated to

\begin{tabular}{lll}
\hline \multicolumn{2}{l}{ Table 1: Fiction used in intervention class } \\
\hline Fiction & Format & Relation to content \\
\hline Honey, I shrunk the kids & Movie clip & $\begin{array}{l}\text { Law of conservation of } \\
\text { mass }\end{array}$ \\
Breaking bad & Television clip & Thermite reaction \\
Chain reaction & Movie clip & Hydrogen flammability \\
Big hero 6 & Movie clip & $\begin{array}{l}\text { Decomposition reaction } \\
\text { The Martian }\end{array}$ \\
& Book excerpt & $\begin{array}{l}\text { Synthesis/decomposition } \\
\text { reaction }\end{array}$ \\
\hline
\end{tabular}

explore the level of content master of students. A survey of content (Appendix 1) and topic interest was also given to students in both contexts. Standard t-tests and p-values were assigned to the achievement data. Finally, informed by the action research plan, act, observe, and reflect cycle the first author maintained a focus of promoting a different kind of discourse and at the same time attempt to respond to the unforeseen obstacles that arose throughout data gathering (Cochran-Smith and Lytle, 1993; Carr and Kemmis, 1986; Kemmis and McTaggert, 1988). To assure equal content coverage, the first author used journaling, classroom artifacts, and in some instances classroom recording to maintain a comparable time on topic for different various covered in both the control and intervention classrooms. We also understood that teachers are uniquely positioned to provide a truly emic perspective by describing how students and teachers together construct new knowledge (Lytle and Cochran-Smith, 1992). Therefore, the collaborative model for this research deferred to the primary teacher's interpretation of data and the secondary role of the second author was to question and interrogate claims suggested by initial findings of the data.

\section{RESULTS FROM INTERVENTION}

\section{Classroom Excerpts}

Classroom discussions were expected to be impacted by the insertion of fiction media to instruction. Most notably, students' questions were more frequent, interest was more quickly piqued in the topic, students were quicker to offer responses to the teacher's questions, and students showed a willingness to challenge other students' inaccurate beliefs during instruction. Examples of these shifts in conversation are examined below and explained in connection to their content relevance.

\section{Chemical Change}

Part of an essential understanding of chemical change and stoichiometry is the notion of conserving mass, accounting for each atom, and their rearrangement. Although the Law of Conservation of Mass had been covered earlier in the academic year, the chemical change lessons observed in this study began with the review of this concept and the intervention featured, Harry Potter and the Sorcerer's Stone and Honey, I Shrunk the Kids. Transfigurations are a central of the former, and the latter contains discrepant events where mass is clearly not conserved. Questioning the possibility of both, the teacher 
asked students to explain the accuracy of objects taking new shapes (Harry Potter.) and the father sweeping up his shrunken children (Honey, I Shrunk...).

Jared: "Well, mass is how much stuff there is in something, right?" [seeing reinforcement]

Julie: "Yea, and when the kids shrunk, their mass didn't change so their weight would be the same."

Jared: "So then, when the dad swept them up, technically he wouldn't have been able to lift the broom!" said Jared.

Clayton: "I don't get it."

[Many overlapping excited student voices]

Ashley: "Clayton, how much do you weigh?!" asked Ashley.

Clayton: "160 pounds."

Eli: "So, if you were shrunk down to smaller than an ant, and your mass was conserved, how much would you weigh?"

Clayton: "I guess I would still weigh 160."

Julie: "So what would happen if your dad tried to sweep antsized you, but you grabbed the broom?"

Clayton: [Realizing his error] "Oh! He wouldn't be able to lift the broom as easy because an extra 160 would be hanging on and then he would think that something was up...But that didn't happen in the movie!"

Jared: "So then the movie was wrong, right? I mean, the kids just got swept up with the broom and the dad didn't even flinch. So they didn't follow the law of conservation of mass! They lost some mass to cause their weight to be less."

After much laughter, students demonstrated disbelief that even something as basic to chemistry as conservation of mass could be ignored in the production of fiction movies. The conversation led to spontaneous connections to other movies including the recent ant man movie where the law of conservation of mass was inconsistently applied. The conversation largely promoted by students allowed the teacher to listen in on explanations from students and attend to commonly documented chemistry misconceptions. When addressing the concepts of combustion, rusting, and even physical changes such as sublimation and evaporation, students more quickly and robustly addressed wrong thinking in their peers like the notion of wood or fuel 'disappearing' rather than being rearranged into carbon dioxide and other compounds. Inserting fiction video in this instance afforded the teacher frequent and recurring opportunities to address directly wrong thinking and recheck the application of science concepts from weeks past.

\section{Reaction Categorization}

Student contributions to class discussions were even more enthusiastic when challenging seemingly impossible special effects surrounding devastation and calamity. In the chain reaction film, a hydrogen plant catches on fire and explodes destroying blocks of a city, but not the heroic actor, Keanu
Reeves. The daring star is portrayed as escaping danger by jumping into a ditch, with Hollywood producers ignoring such effects as the depletion of all oxygen from the vicinity. After introducing the scene, chemistry students immediately started arguing about the feasibility.

Anna: "Wait a second, are you kidding me? There is NO WAY that a hydrogen explosion could do THAT!"

Teacher: "What kind of reaction is this?"

[Many overlapping excited student voices]

Students: "COMBUSTION!"

Jared: So, we did this in class, right? We did a single replacement reaction and collected the hydrogen. Then we put that lit stick into it and it barked at us. That told us we had hydrogen. So WHY would they show an explosion like that one!?"

Rick: "Well, remember the Hindenburg! That was part a combustion of hydrogen and that was a big fire!"

Anna: "Yeah...Except it didn't destroy the people on the ground. They could handle the situation."

Once again, the class discussion was more animated when a student challenged the reality of the portrayal. Students did not wait to raise their hand or seek permission to respond. Criticism and rebuttal was apparently fair game for the new form of science class discussion. When Anna did not accept the portrayed magnitude of the devastation, she objected. Students, however, were quick to not only categorize the synthesis reaction but also correctly name the example. The teacher allowed students to raise challenges like, "is it possible?" and students were readily able and willing to answer - engaging in such teacher prompts as, "let's explore this further."

Students not only recalled accurately the concepts and experiments they had performed together before this unit, they but also were practicing the composition of argumentation highlighted in today's NGSS reform (NGSS Lead States, 2013). During such activities, shifts in content authority were observed which were characterized best by deviation from a singular form of content authority (e.g., teacher, textbook) to a focus upon available evidence as authority. The above discussion representing the larger classroom discourse where students practiced a form of scientific discourse which required them to decide what counted as evidence (lab experience over movie), whether evidence was used appropriately (history over special effects), and who decided the veracity of claims or the "truth" of the outcomes (students over movie goers). Just as reformers call for scientifically literate citizens to be critical consumers of information, students engaged in the process of debunking poor representations of science in the fiction excerpts they were presented with as supplemental resources.

\section{Interviews}

Interviews revealed specific impacts of science fiction videos on instruction. Of the nine intervention group students interviewed, 
most indicated that science videos had made instruction more interesting, enjoyable, and increased interest in chemistry as shown in Figure 1. Most students in the experimental group reported that fiction videos helped them to understand difficult concepts. Students thought videos were useful in showing real-life reactions, but it also served to engage students who typically did not enjoy chemistry. One student reported in the exit interview, "I'm usually [bad] at science, like, I don't get it... but I actually got it this time so it was fun." However, students also reported that their favorite and most helpful part of the unit was not the videos. Instead, most agreed that the labs they performed were enjoyable and the most helpful in constructing their understanding about difficult concepts. Figure 1 shows some of the other benefits noted by chemistry students including the assistance in understanding concepts, the enhancement of the overall learning experience, and increased interest in science.

\section{Assessments}

As expected, the pre-assessment scores for both control and experimental classroom students demonstrated a shallow understanding of fundamental concepts related to chemical changes and reactions. In the control class, the pre-assessment mean and median were a score of 8 out of 100 possible points. For the experimental class, the pre-assessment mean and median were 7 and 6, respectively, as shown in Table 2.

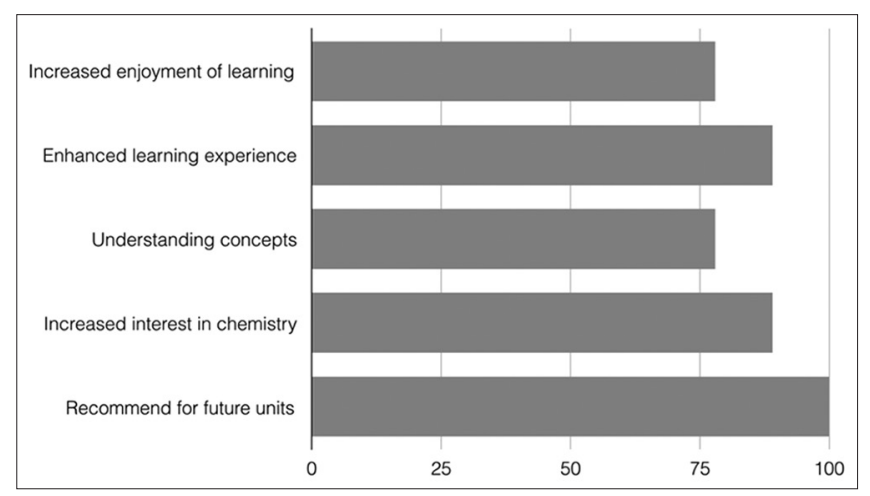

Figure 1: Impacts of science fiction videos on instruction

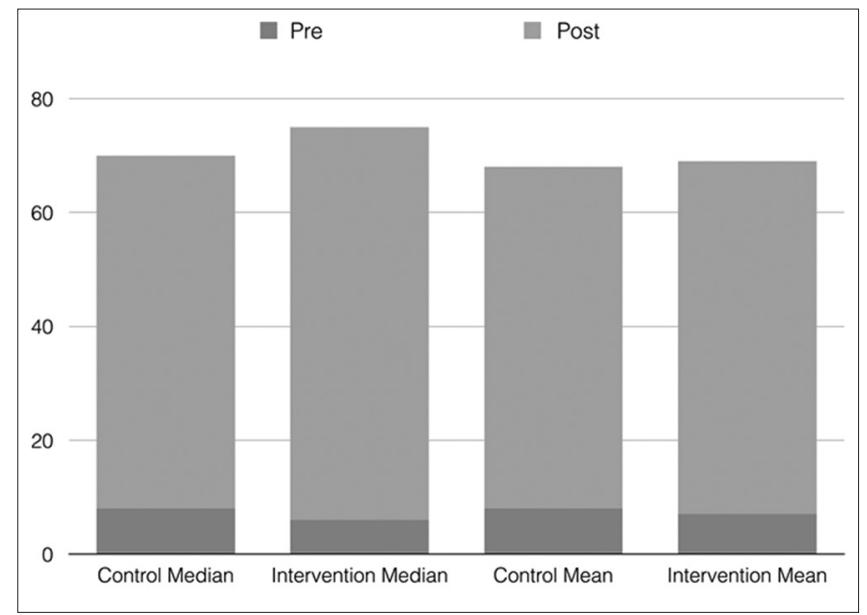

Figure 2: Pre- and post-assessments for control and intervention classrooms
The post-assessments t-tests were split into two groups, one comparing only chemical reaction questions addressed in the video and the other comparing overall unit competency. Surprisingly, there were only nominal differences in the means and medians for the post-assessment. For the control group mean and median scores were 60 and 62, respectively (Figure 2), while the intervention group demonstrated a competency of 69 and 80 , respectively. While the differences between the chemical reaction questions and total final assessments were slightly greater for the intervention group, the differences were statistically insignificant.

\section{DISCUSSION}

As researchers and teachers who believe that students and teachers socially construct meaning in classrooms, we do not promote this study's findings as definitive, generalizable, nor a good representation of controlled experimentation. To the contrary, we understand that it is admittedly impossible for a teacher to change who they are and interact in fundamentally different ways, whether intentionally or unintentionally, altering their social positioning within an instructional context without affecting student learning. We believe it is not possible to fully design nor contrive a learning environment to claim definitively one pedagogical approach is superior to another based solely upon the delivery method of the same teacher during different hours of the instructional day. Furthermore, we believe it is also borderline unethical behavior to intentionally deny to some students the benefit of some superior pedagogical approach or research treatment, while denying it to another group - if

\begin{tabular}{|c|c|c|}
\hline Scores & $\begin{array}{c}\text { Block 1 } \\
\text { (control) }\end{array}$ & $\begin{array}{c}\text { Block 3 } \\
\text { (intervention) }\end{array}$ \\
\hline Pre-assessment mean & 8 & 7 \\
\hline Pre-assessment median & 8 & 6 \\
\hline $\begin{array}{l}\text { Post-assessment mean (chemical reaction } \\
\text { questions) }\end{array}$ & 60 & 62 \\
\hline $\begin{array}{l}\text { Post-assessment median (chemical } \\
\text { reaction questions) }\end{array}$ & 62 & 69 \\
\hline Post-assessment mean (total test) & 69 & 69 \\
\hline Post-assessment median (total test) & 69.5 & 80 \\
\hline
\end{tabular}

\begin{tabular}{lccc}
\hline Table 3: Statistical results & & \\
\hline Scores & t-value & $\begin{array}{c}\text { t-critical } \\
\text { value }\end{array}$ & $\mathbf{p}$ \\
& & & \\
\hline Control & -11.057 & 1.7138 & $5.56 \times 10^{-11}$ \\
$\quad$ Chemical reaction questions & -18.1386 & 1.71387 & $2.01 \times 10^{-15}$ \\
$\quad$ Total test & & & \\
Intervention & -9.9269 & 1.7171 & $6.89637 \times 10^{-10}$ \\
$\quad$ Chemical reaction questions & -12.5033 & 1.7171 & $8.99 \times 10^{-12}$ \\
$\quad$ Total test & & & \\
Control versus intervention & 0.3107 & 1.6794 & 0.378 \\
$\quad$ Chemical reaction questions & $6.68 \times 10^{-5}$ & 1.6794 & 0.4999 \\
$\quad$ Total test & & & \\
\hline
\end{tabular}


we, as researchers, truly believed it was helpful. Rather, we as researchers freely acknowledge that the first author was neither a purely constructivist nor a dogmatic didactic teacher, but instead, as Florio-Ruane (1987) once described teacher researchers, as individuals with understanding of "webs of significance" (p. 186) that no outsider has access to. We, in turn, leveraged this instructor's insight to get access to student thinking and her construction of scientific concepts through the tools of action research. What we found helped to inform her efforts and explore more deeply the effect of fiction on her students' fundamental conceptions of chemistry.

Our first claim was borne out of the set of evidence gathered from teacher-student interactions throughout the weeks of instruction. When students were afforded the opportunity to explore, challenge, and defend claims about events portrayed in science fiction, students' questions became more directed toward making sense of the application than arriving at final, accurate answers. As these questions began to open up the dialogue during traditional teacher-led discussions, studentto-student dialogue became more natural. In part, this was due to the familiarity of the example and in some cases due to the shift of authority over answers. When the teacher stepped back in part from authoritatively providing confirmation and an authoritative scientific answer and allowed students to question and ponder examples they had seen, students answered one another's questions more often. Because students were contributing more and openly constructing the meaning of examples through dialogue, the teacher gained more insight regarding the challenges of other students. In this way, the fiction examples served as multiple opportunities for the practice of formative assessments that are prescribed throughout research literature on student learning.

The practice of having students contribute more to classroom discussions is a natural motivator for students. When they feel they are being listened to and their ideas matter, they are unsurprisingly more inclined to report they are enjoying the lesson. For this reason, we cannot claim that the inclusion of fiction was itself the reason for increase in richness of student contributions to classroom dialogue. Students reported an increased enjoyment of the lessons and a greater interest in the topics of chemistry in general. The incorporation of fiction may simply be one of many ways to make classroom more interactive, enjoyable and interesting. Although it is not possible to claim this was the direct result of incorporating fiction, such an intervention was associated with increased possibilities to challenge, disagree, and debate in ways that enhanced student learning and attitudes when supplemented to the existing pedagogical orientation toward teaching chemistry. The use of fiction media assisted in changing the nature of chemistry discussions in the classroom context and allowed for skepticism and a more critical approach toward the world and observed events. This finding supports other similar studies, but unlike other authors, we do not believe our results have much to do with the more superficial attributes of the movies themselves. For example, teachers may assume that extemporaneous features such as public popularity of actors, box office success of movies, release dates, or even the quality of the special effects would be the integral factors for determining the heightened student interest or richness of students' conversations for the inserted fiction excerpts. We have reason to believe this was not the case. As in the case of Honey, I Shrunk the Kids, this movie was not popular among our students, nor was it one they would check out of the library to watch again. However, their resultant discussions were lively and their arguments cogent when it was integrated into discussions of science content.

The outcome of the assessments confounded the first author's predictions in two ways. First, there was an expected increase for students' achievement on post-assessment scores. After experiencing the increased quality of student contributions, she was confident the scores on correlating questions would improve. To her surprise, the content knowledge attainment indicated by test performance was statistically insignificant. Despite her conviction that she was 'on to something' in her teaching that would increase student understanding of content, our research was consistent with the research which preceded ours regarding test scores. We were unable to make any solid connection between achievement scores and the use of fiction for teaching science. That is not to say that there was no additional learning in the class, we were simply unable to prove with any significance what we believed were changes in student thinking.

The second surprise for the instructor borne out by evidence was the peripheral benefits fostered from the use of fiction in chemistry class for students who exhibited lower achievement on end of unit chemistry tests throughout the year. The first author observed that students who engaged the most and gave the most thoughtful answers during both large class discussions and small group contributions were typically identified as ones that had struggled or who had achieved in the lower quartile throughout the year before this instructional period. She did not expect that the students who had struggled typically would offer the best contributions to classroom discussions. The higher achieving students were less enthusiastic and asked more concrete questions. Indeed, consistent with the findings of past studies (Brzenk et al., 2000; Dubeck et al., 1990; Surmeli, 2012), the insertion of fiction excerpts increased the interest of students who have typically underachieved in science and not regularly participated in open conversations about content. This could have been due in part to the cross-disciplinary nature of the excerpts introduced or perhaps even to the variation offered to students in the ways in which they could access content through renegotiated classroom discourse norms.

These findings lead us to conclude that there is a weaker link between standard assessments and the kinds of forward progress teachers may hope for in opening up classroom dialogue. If teachers are to renegotiate classroom discourse toward a stance for critical thinking, development of arguments, and shift the classroom conversation away from teachers telling information 
and conveying authoritative expertise, they cannot rely on test scores to reinforce their efforts. Student achievement may not improve at all, despite the shifts in students' responses, interest, or classroom enjoyment. Therefore, if teachers do desire to make changes and study the impacts of these changes, perhaps standard tests are not the method of choice they to demonstrate growth in their students' learning or improvements in teachers' practices. Rather, they should find other, more authentic ways to examine student thinking and discourse before making changes in their pedagogy. Choosing clinical interviews, students' problem solving, or even more open-ended questions like those represented on the PISA exams other countries outside the U.S. may serve as better informants of student thinking (Bybee et al., 2009; Cresswell and Vayssettes, 2006).

More practical considerations for teaching were also generated from both the pilot and the follow-up study. These recommendations pertained to both the selection of fiction as well as the nature of instruction. From our observations, we recommend teachers' pay little attention to the popularity of the film, the quality of special effects, the overall cinematic value of the film, quality of acting, box office budgets, or popularity of the actors. None of these factors were helpful in selecting engaging fiction. Rather, examples selected that were most impactful included ones which: Addressed directly the concepts in question, presented direct evidence to refute or confirm claims inferred by the fictional movie script or text, or led to divergent conversations rather than confirming the "truth" of scientific interpretation. In addition, though there were a wide range of different teaching strategies available to integrate fiction, the most impactful strategies to increase student contributions was the use of fiction prompts for small group discussions, the use of fiction as discrepant events, and the use of video vignettes to highlight, accentuate, contest, or supplement examples during whole class discussions with intentional opportunities for student questioning. The most expeditious implementation was the use of video vignettes from digital sources such as DVDs or YouTube. It is important that teachers intending to insert vignettes from film should pay close attention to copyright restrictions on media they access, utilize, or assign for students to consider.

Although we were unable to make any solid connection between the planned intervention and achievement scores on standard teacher-made tests, which reflected state assessments; the use of fiction media was helpful in changing the nature of chemistry discussions in the classroom context and allowed for skepticism and a more critical approach toward the world and observed events. The resultant classroom discussions surrounding the incorporation of fiction were lively and their arguments cogent when fiction was an artifact integrated into science content discussions.

There is little argument that science adolescents today spend a substantive amount of time observing and interacting with entertainment media. Whether real or imagined, the use of fiction in the classroom allowed students to relate science to life as they saw and experienced it. Our findings lead us to ask related questions for future study like:

- Are there certain movie genres, clips, special effects, or features that are particularly helpful or particularly harmful to promoting scientific thinking among chemistry students?

- Why didn't notable changes in classroom conversations translate directly into chemistry achievement on standardized questions? Were there really no content knowledge gains or can they best be measured through more specific clinical interviews instead of achievement test questions?

- Can results from more modern, qualitative, and formative assessments (like responses to media clips) be used to prompt better assessment measures of children's thinking in the real world?

- What are best teaching practices associated with the use of science media for teaching chemistry beyond simple selection and insertion during instruction? Are these practices vary for different content areas (e.g., earth science and movies like San Andreas or 2012)?

We look to future research to elaborate further regarding these matters, but one thing is clear: The establishment of an open and argumentative classroom communication fostered a form of scientific literacy reforms demand. Modern conceptions of science classroom discourse values the use evidence to construct arguments, extinguish misconceptions, foster the growth of the imagination and creativity, and increase the overall positive attitudes of students toward science. Fiction media affords educators the opportunity to explain reality and teach students how to analyze scientific principles. Teachers can promote better understanding by means of providing them with a greater ability to visualize abstract concepts such as nuclear detonations, violations of conservation of mass or energy, exaggerated geological, biological, or physical phenomenon fault ruptures during earthquakes, even when concepts are portrayed incorrectly through supplemental reading and media. The provision of fiction resources can impact students future discussions of the ethical, possible, and political influences of science. It can also assist students to visualize a future that may not be desirable. Through strategies of this type, students can subsequently take the imagery and become advocates for change, creating preventative measures for a more positive future.

\section{REFERENCES}

Asimov, I. (1967). Is Anyone There? New York: Doubleday.

Bixler, A. (2007). Teaching evolution with the aid of science fiction. American Biology Teacher, 69, 337-339.

Brzenk, R., Moore, A., Alfano, M.J., Buckley, P.T., Newman, M.E., \& Dunnivant, F.M. (2000). Understanding the greenhouse effect: Is global warming real? An integrated lab-lecture case study for non-science majors. Journal of Chemistry Education, 77(12), 1602.

Bybee, R., McCrae, B., \& Laurie, R. (2009). PISA 2006: An assessment of scientific literacy. Journal of research in Science Teaching, 46(8), $865-883$.

Carr, N. (2011). The Shallows: What the Internet is doing to Our Brains. New York: WW Norton \& Company. 
Carr, W., \& Kemmis, S. (1986). Becoming Critical: Education, Knowledge, and Action Research. Geelong, Australia: Deakin University.

Chandler, D. (2002). Start using 'Hollywood physics' in your classroom! The Physics Teacher, 40, 420.

Clough, G.W. (2011). Increasing Scientific Literacy a Shared Responsibility. Available from: http://www.si.edu/Content/Pdf/About/Secretary/ Increasing-Scientific-Literacy-a-Shared-Responsibility.pdf. [Last accessed on 2017 Sep 27].

Cochran-Smith, M., \& Lytle, S.L., (Eds.) (1993). Inside/Outside: Teacher Research and Knowledge. New York: Teachers College Press.

Cresswell, J., \& Vayssettes, S. (2006). Assessing Scientific, Reading and Mathematical Literacy: A Framework for PISA 2006. Available from: http://www.oecd.org/edu/school/ assessing scientific reading and mathematicalliteracya framework forpisa 2006. htm\#TOC. [Last accessed on 2017 Sep 27].

Cruz, R.A.L. (2013). Aliens in the classroom: Fantastical creatures as tools in teaching biology. American Biology Teacher, 75(4), 257-261. Available from: http://www.bioone.org/doi/full/10.1525/abt.2013.75.4.6. [Last accessed on 2017 Oct 05].

Dark, M.L. (2005). Using science fiction movies in introductory physics. The Physics Teacher, 43, 463.

Dubeck, L.W., Bruce, M.H., Schmucker, J.S., Moshier, S.E., \& Boss, J.E. (1990). Science fiction aids science teaching. The Physics Teacher, 28, 316-318.

Flynn, N. (2010). Design your own disease assignment: Teaching students to apply metabolic pathways. Journal of Chemistry Education, 87(8), 799-801.

Frayling, C. (2013). Mad, Bad and Dangerous? The Scientist and the Cinema. Chicago: University of Chicago Press, Reaktion Books.

Florio-Ruane, S. (1987). Sociolinguistics for educational researchers. American Educational Research Journal, 24, 185-197.

Frey, C.A., Mikasen, M.L., \& Griep, M.A. (2012). Put some movie wow! In your chemistry teaching. Journal of Chemical Education, 89, 11381143.

Harwood, W.S., \& McMahon, M.M. (1997). Effects of integrated video media on student achievement and attitudes in high school chemistry. Journal of Research in Science Teaching, 34(6), 617-631.

Hofstein, A., \& Kempa, R.F. (1985). Motivating strategies in science education: Attempt at an analysis. The European Journal of Science Education, 7(3), 221-229.

Kemmis, S. (2010). Research for praxis: Knowing doing. Pedagogy, Culture and Society, 18(1), 9-27.

Kemmis, S., \& McTaggert, R. (1988). The Action Research Planner. $3^{\text {rd }}$ ed. Geelong, Australia: Deakin University.

Labianca, D.A., \& Reeves, W.J. (1981). Chemistry and detective fiction an interdisciplinary program for the non-science major. Journal of Chemical Education, 58(8), 683-686.

Laprise, S., \& Winrich, C. (2010). The impact of science fiction films on student interest in science. Journal College Science Teaching, 40(2), 45.

Lemke, J. (1990). Talking Science: Language, Learning and Values. Norwood, NJ: Ablex Publishing Corporation.

Liberko, C.A. (2004). Using science fiction to teach thermodynamics: Vonnegut, ice-nine, and global warming. Journal Chemical Education, 81(4), 509.

Lin, K. (2014). Effects of science fiction films on junior high school students' creative processes and products. Thinking Skills and Creativity, 14, 87-97.
Lumpe, A.T., Haney, J.J., \& Czerniak, C.M. (2000). Assessing teachers beliefs about their science teaching context. Journal of Research in Science Teaching, 37(3), 275-292.

Lytle, S., \& Cochran-Smith, M. (1992). Research as a way of knowing. Harvard Educational Review, 62, 447-474.

McTaggart, R. (1996). Issues for participatory action researchers. In: ZuberSkerritt, O., (Ed.), New Directions in Action Research. Washington, DC: Falmer Press. pp. 243-255.

Marks, G.H. (1978). Teaching Biology with Science Fiction. American Biology Teacher, 40(5), 275-279. Available from: http://www.jstor.org/ stable/4446243. [Last accessed on 2017 Oct 05].

Milanick, M.A., \& Prewitt, R.L. (2013). Fact or fiction? General chemistry helps students determine the legitimacy of television program situations. Journal of Chemical Education, 90, 904-906.

Mintzes, J.J., Wandersee, J.H., \& Novak, J.D., (Eds.) (2005). Teaching Science for Understanding: A Human Constructivist View. Chicago: Academic Press.

Miller, J.D. (1983). Scientific literacy: A conceptual and empirical review. Daedalus, 112(2), 29-48.

Miller, J.D. (1987). Scientific literacy in the United States. In: Evered, D., \& O'Conner, M., (Eds.), Communicating Science to the Public: Ciba Foundation Conference. Chichester, UK: John Wiley \& Sons.. -.

Moje, E.B., Ciechanowski, K.M., Kramer, K., Ellis, L., Carrillo, R., \& Collazo, T. (2004). Working toward third space in content area literacy: An examination of everyday funds of knowledge and discourse. Reading Research Quarterly, 39(1), 38-70.

Morais, C. (2015). Storytelling with chemistry and related hands-on activities: Informal learning experiences to prevent "chemophobia" and promote young children's scientific literacy. Journal of Chemical Education, 92, 58-65.

NGSS Lead States. (2013). Next Generation Science Standards: For States, by States. National Academies Press. Available from: https://www.nap. edu/download/18290. [Last accessed on 2017 Sep 27].

Nunan, E.E., \& Homer, D. (1981). Science, science fiction, and a radical science education. Science Fiction Studies, 8(3), 311-330.

Ober, J., \& Krebs, T. (2009). Chemical elements in fantasy and science fiction. Journal of Chemical Education, 86(10), 1141.

OECD. (2012). Programme for International Student Assessment 2015 Scientific Literacy Assessment Framework. Available from: https:// www.oecd.org/edu/EAG\%202012 e-book EN 200912.pdf. [Last accessed on 2017 Sep 27].

Oppenheimer, T. (2003). The Flickering Mind: The False Promise of Technology in the Classroom, and How Learning Can be Saved. New York: Random House.

Rodriguez, A.J. (2015). What about a dimension of engagement, equity, and diversity practices? A critique of the next generation science standards. Journal of Research in Science Teaching, 52(7), 1031-1051.

Rodriguez, A.J., \& Kitchen, R.S. (2005). Preparing Mathematics and Science Teachers for Diverse Classrooms: Promising Strategies for Transformative Pedagogy. Hillsdale, NJ: Lawrence Erlbaum Associates.

Ryan, T.G. (2009). The evolving teacher, leader and action researcher. The International Electronic Journal of Elementary Education, 1(3), 202217. Available from: http://www.iejee.com/1_3_2009/ryan.pdf. [Last accessed on 2017 Sep 27]

Surmeli, H. (2012). Examination the effect of science fiction films on science education students' attitudes towards STS course. Procedia-Social and Behavioral Sciences, 47, 1012-1016. 


\section{Example Post-assessment Questions:}

In a chemical reaction, the type of products obtained is largely determined by which part of the reacting chemicals?
a. Protons
b. Electrons
c. Neutrons
d. Nuclei.

In the chemical reaction in which sucrose is heated and decomposes to form carbon dioxide and water, which of the following is a reactant?
a. Sucrose
b. Carbon dioxide
c. Water
d. Heat.

Which of the following is true for all chemical reactions?

a. The total mass of the reactants increases

b. The total mass of the products is greater than the total mass of the reactants

c. The total mass of the products is less than the total mass of the reactants

d. The total mass of the reactants equals the total mass of the products.

What are the coefficients that will balance the skeleton equation below?

$\mathrm{AlCl}_{3}+\mathrm{NaOH} \rightarrow \mathrm{Al}(\mathrm{OH})_{3}+\mathrm{NaCl}$
a. $1,3,1,3$
b. $3,1,3,1$
c. $1,1,1,3$
d. $1,3,3,1$.

Chemical equations must be balanced to satisfy

a. The law of definite proportions

b. The law of multiple proportions

c. The law of conservation of mass

d. Avogadro's principle.

What are the missing coefficients for the skeleton equation below?

$\mathrm{Cr}(\mathrm{s})+\mathrm{Fe}\left(\mathrm{NO}_{3}\right)_{2}(\mathrm{aq}) \rightarrow \mathrm{Fe}(\mathrm{s})+\mathrm{Cr}\left(\mathrm{NO}_{3}\right)_{3}(\mathrm{aq})$
a. $\quad 4,6,6,2$
b. $\quad 2,3,2,3$
c. $\quad 2,3,3,2$
d. $1,3,3,1$.

In a combustion reaction, one of the reactants is

a. Hydrogen

b. Nitrogen

c. Oxygen

d. A metal

The reaction $2 \mathrm{Fe}+3 \mathrm{Cl}_{2} \rightarrow 2 \mathrm{FeCl}_{3}$ is an example of which type of reaction?

a. Combustion reaction

b. Single replacement reaction

c. Combination (synthesis) reaction

d. Decomposition reaction.

The equation $\mathrm{Mg}(\mathrm{s})+2 \mathrm{HCl}(\mathrm{aq}) \rightarrow \mathrm{MgCl}_{2}(\mathrm{aq})+\mathrm{H}_{2}(\mathrm{~g})$ is an example of which type of reaction?

a. Combination (synthesis) reaction

b. Single replacement reaction

c. Decomposition reaction

d. Double replacement reaction.

The equation $\mathrm{H}_{3} \mathrm{PO}_{4}+2 \mathrm{KOH} \rightarrow \mathrm{K}_{3} \mathrm{PO}_{3}+3 \mathrm{H}_{2} \mathrm{O}$ is an example of which type of reaction?

a. Double replacement reaction

b. Combination reaction

c. Decomposition reaction

d. Single replacement reaction.

The equation $2 \mathrm{C}_{3} \mathrm{H}_{7} \mathrm{OH}+9 \mathrm{O}_{2} \rightarrow 6 \mathrm{CO}_{2}+8 \mathrm{H}_{2} \mathrm{O}$ is an example of which type of reaction?

a. Combustion reaction

b. Single replacement reaction

c. Double replacement reaction

d. Decomposition reaction.

When an acid reacts with a base, what compounds are formed?
a. A salt only
b. Water only
c. Metal oxides only
d. A salt and water. 


\section{Balancing and Identifying}

Balance the following equations. If they are already balanced, be sure to make that statement. State whether each equation is synthesis, decomposition, single replacement, double replacement, or combustion.
a. $\mathrm{Na}_{3} \mathrm{PO}_{4}+$
$\mathrm{KOH} \rightarrow$ $\mathrm{NaOH}+$ $\mathrm{K}_{3} \mathrm{PO}_{4}$
b. $\longrightarrow \mathrm{P}_{4}+{ }_{\mathrm{O}} \rightarrow$ c. $\quad \mathrm{NaF}+\quad \mathrm{Br}_{2} \rightarrow \quad \mathrm{NaBr}+\ldots \quad \mathrm{F}_{2}$
d. $\mathrm{CH}_{4}+$
$\mathrm{CO}_{2}+$ $\mathrm{F}_{2}$
$\mathrm{KCl} \rightarrow$
$\mathrm{O}_{2} \rightarrow$
$\mathrm{Cl}_{2}$ $\mathrm{H}_{2} \mathrm{O}$

Example Interview Questions:

1. Did you enjoy the unit on chemical reactions? Why or why not?

2. What was your favorite part from the unit?

3. Do you think using fiction films and literature enhanced your experiences of the unit?

4. Do you feel that it helped you understand difficult topics?

5. Did the use of fiction increase your interest in the subject?

6. Would you recommend using fiction film and literature for other chemistry units?

7. What recommendations do you have for using fiction in chemistry in the future? 